\title{
Vulnerability of several conifers to air embolism
}

\section{HERVÉ COCHARD}

\author{
Laboratoire d'Ecophysiologie Forestière, INRA, Centre de Nancy, F-54280 Champenoux, France
}

Received August 14, 1991

\begin{abstract}
Summary
Hydraulic properties of xylem in seven species of conifer were studied during late winter and early spring 1991. Vulnerability to cavitation and air embolism was investigated using hydraulic conductivity and acoustic techniques. Embolisms were induced in branches excised from mature trees by air-drying them in the laboratory. Both techniques gave comparable results indicating that they both assess the same phenomenon. Within a tree, vulnerability was related to the permeability of the xylem, the largest stems tended to cavitate before the smallest ones when water deficits developed in a branch. Interspecific comparisons showed large differences in the xylem water potential needed to induce significant embolism, values ranged from $-2.5 \mathrm{MPa}$ in Pinus sylvestris to $-4 \mathrm{MPa}$ in Cedrus atlantica, but these differences did not correlate with differences in the xylem permeability of the species. The vulnerability of a species to air embolism was found to be consistent with its ecophysiological behavior in the presence of water stress, drought-tolerant species being less vulnerable than drought-avoiding species.
\end{abstract}

\section{Introduction}

Conifers have successfully colonized a variety of environments ranging from hot and dry to cold and wet. Nevertheless, the water-conducting conduits, the tracheids, vary little in dimension among conifer species. Since the work of Dixon (1914) on the ascent of sap, it has been known that the sap is transported under tension in the tracheids, i.e., in a physically metastable state. The xylem water potential of conifers in the field varies greatly according to environmental conditions and the species. Aussenac and Valette (1982) reported a minimum xylem potential of $-4 \mathrm{MPa}$ for Cedrus atlantica but only -2.2 MPa for Pinus sylvestris growing in a mixed stand. Evidence has accumulated in the past few years that tracheids and vessels may be subject to xylem dysfunction, caused by embolism following cavitation induced by water stress (see review by Tyree and Sperry 1989). The vulnerability of woody plants to cavitation is poorly documented. Sperry and Tyree (1990) found large differences in vulnerability in a comparative study of three conifers, with the most drought-adapted species (Juniperus virginiana) being the least vulnerable. Vulnerability profiles can be used to estimate the theoretical limits of water transport in the xylem (Tyree and Sperry 1989) and may provide information about the ecophysiological behavior of the plant.

In this study, I investigated the vulnerability of xylem to cavitation in several species of conifers planted in regions of France where water stress commonly develops during the summer. I tested the hypothesis that species manifesting different ecophysiological responses when subjected to water stress also differ in the vulnerability of their xylem to embolism. Embolism in trees was tested by mean of 
two techniques, one based on acoustic detection and the other on hydraulic conductivity measurements. Systematic comparison of these methods on the same materials have seldom been done and their comparability has not been demonstrated.

\section{Materials and methods}

\section{Plant material}

Experiments were conducted on 5-10-year-old branches excised from mature trees growing in the Arboretum of Amance, near Nancy, France $\left(48^{\circ} 44^{\prime} \mathrm{N}, 6^{\circ} 14^{\prime} \mathrm{E}\right.$, elevation $250 \mathrm{~m}$ ). Species were: Cedrus atlantica (Endl.) Carr., Cedrus deodara (Roxb.) G. Don ex Loud., Pinus sylvestris L., Picea abies (L.) Karst., Pseudotsuga menziesii (Mirb.) Franco, Abies bornmulleriana Mattf., Abies alba Mill. Specific experiments were performed on Picea abies var. virgata. Branches were collected from the crown of each tree with a telescopic pruning pole during late winter and spring 1991 after a moderately cold winter (minimum temperature was $-8{ }^{\circ} \mathrm{C}$ ). Preliminary results have shown that natural embolism in these trees was always very low during this period.

\section{Induction of embolisms}

Vulnerability profiles, which are represented by plots of embolism versus leaf water potential, were constructed by drying branches to various water potentials to induce embolisms ranging from 0 to 100 percent. Two techniques were used to induce air embolisms in the xylem.

For all the species, air embolisms were induced by allowing the branches to desiccate on a laboratory bench or in a phytotron. To facilitate drying, the bark was occasionally removed from the proximal part of the stems, always leaving the segment destined for an embolism measurement intact. Leaf water potential was monitored at regular intervals on excised shoots with a Scholander pressure chamber. When a suitable xylem pressure was reached, the branches were wrapped in a black plastic bag overnight to stop the drying and to allow air to diffuse in the newly cavitated tracheids. Immediately after the cavitation events the lumen of the tracheid was filled with a near-vacuum gas phase that progressively equilibrated with the atmospheric pressure. When the branches were large enough to provide sufficient material, sub-branches were excised from the main branch and treated as above.

For one species (Abies alba), a second method was used to induce air embolisms. Seven fully hydrated branches, about $30-40 \mathrm{~cm}$ long and 3-4-year-old, were each wrapped in a plastic bag and enclosed in a large Scholander pressure chamber. The pressure was increased to a specific value (between $1 \mathrm{MPa}$ and $4 \mathrm{MPa}$ ), and maintained constant (within $1 \%$ of pressure probe accuracy) with an automatic regulator. When the equilibrium pressure was reached (after 1 to 4 hours, depending on the applied pressure), air pressure was released within a few minutes. As before, branches were left overnight wrapped in an airtight plastic bag before conductivity was measured. The vulnerability curves constructed from measurements obtained 
with this method were compared to the vulnerability curves derived from measurements obtained from the routine air-dehydration method.

\section{Measurement of the extent of embolisms}

Two techniques were used to assess the extent of embolisms in the xylem. Air embolisms were first estimated by their effect on loss of hydraulic conductivity in the xylem (Sperry 1985, Sperry et al. 1988a). The technique is based on the measurement of hydraulic conductivity of samples $\left(\mathrm{kg} \mathrm{s}^{-1} \mathrm{~m}^{-1} \mathrm{MPa}^{-1}\right)$ before and after repeated perfusions of $0.1 \mathrm{MPa}$ pressurized solution that progressively dissolve the embolisms in the tracheids. Hydraulic conductivity was calculated by measuring the water mass flow passing through samples connected to a constant pressure reservoir $(6 \mathrm{kPa})$. Water mass flow was measured with an analytical balance interfaced with a computer. The pressurized solution was de-gassed distilled water, acidified with $\mathrm{HCl}(\mathrm{pH} 2)$ to limit bacterial and fungal growth. The solution was kept in an air-free beach ball enclosed in a $0.1 \mathrm{MPa}$ pressure water tank and connected to two $45 \mathrm{~mm}$ diameter, $0.2 \mu \mathrm{m}$ in-line filters. Before measurement, the water-stressed branches were soaked in water for about 1 hour to relax the xylem tension. From each branch, 10 segments free of side-branches, $1.8-2.5 \mathrm{~cm}$ long and $0.05-0.5 \mathrm{~cm}$ in diameter (without bark) were excised from shoots 2 to 4(5) years old (age was not checked on the two Cedrus species). Samples were cut under water with a new razor blade, the bark was removed and the samples were fitted into $3 \mathrm{~mm}$ internal diameter Exacanal tubing connected to miniature 3-way stopcocks. Teflon tape was wrapped around the samples to prevent leaks. The apparatus held 30 samples at a time. After measurements, sample length and mean diameter were measured to calculate the permeability (conductivity per cross sectional area) of each sample.

Vulnerability to cavitation was also investigated using a model 4615 drought stress monitor (Physical Acoustic Corp., Lawrenceville, NJ) that detects ultrasonic acoustic emissions (AEs). One or two 5-7-year-old branches, $1 \mathrm{~m}$ long, were cut from the same trees used for the conductivity measurements, recut under water and allowed to rehydrate for about 1 hour. Branches were then placed in a phytotron $\left(25^{\circ} \mathrm{C}, 40 \%\right.$ relative humidity, and with the light off to limit transpiration), with the base of the branch still in water. An I51I transducer (PAC, Lawrenceville, NJ) was clamped on a 3-year-old segment ( 3 to $7 \mathrm{~mm}$ diameter) with a constant force of 30 Newtons. For best contact between the transducer and the xylem, the bark was removed and the wood covered with vacuum grease, which also prevented superficial drying around the transducer. The "Acoustic Emission Amplification Gain" (dB) of the drought stress monitor was adjusted so that a nonsignificant number of AEs was recorded on a well-hydrated branch ( $76 \mathrm{~dB}$ in this study). This gain was maintained for all of the experiments. Other setup parameters were the default ones for the instrument. After a delay of about $30 \mathrm{~min}$, the phytotron light was switched on $\left(260 \mu \mathrm{mol} \mathrm{m}^{-2} \mathrm{~s}^{-1}\right)$, and the branch was removed from the water and allowed to dehydrate until $\mathrm{AE}$ production was less than 10 AEs per minute. Bark at the base of the branches was occasionally removed to accelerate dehydration. The xylem water potential was measured with a pressure bomb on excised shoots or needles. A representative 

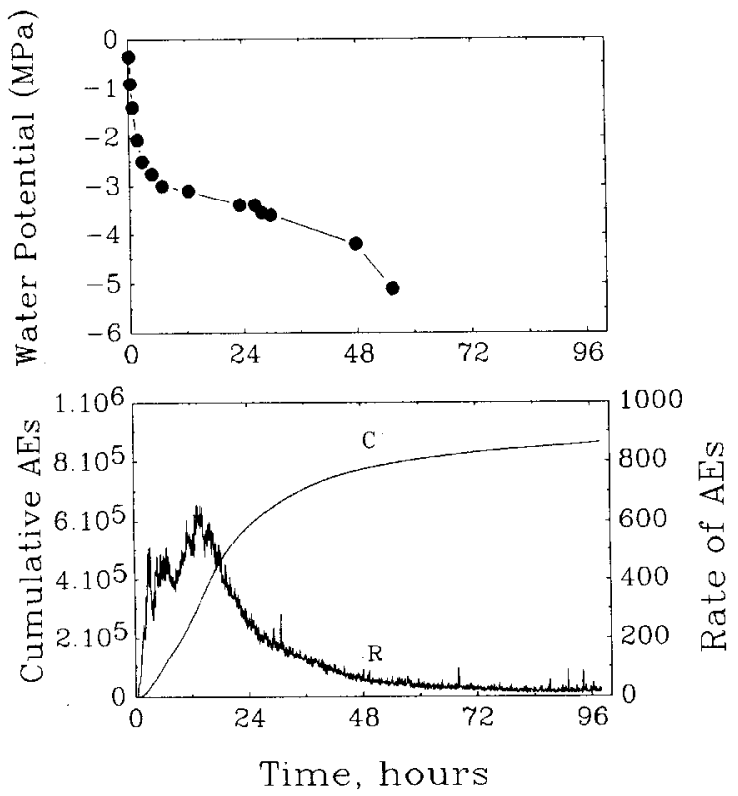

Figure 1. Changes in leaf water potential and acoustic emissions during air dehydration of an excised Abies alba branch that was initially waterlogged. Upper: leaf water potential (MPa); lower left: cumulative AE count (curve C); lower right: AE count rate in counts per minute (curve $\mathrm{R}$ ).

experiment is shown in Figure 1 where the time course of xylem water potential, the cumulative $\mathrm{AEs}$ and the $\mathrm{AE}$ rate are plotted.

To determine the maximum distance at which cavitation events can be detected by the I51I acoustic transducer, Picea abies var. virgata samples 1 to $10 \mathrm{~cm}$ long and 3 $\mathrm{mm}$ in diameter, were excised from annual growth segments, debarked, centered on the transducer, clamped with a constant 30 Newton force and left to dehydrate until the AEs ceased.

\section{Results}

Conductivity of conifer wood

For each species, the relationship between saturated conductivity (after refilling) and sample diameter, after log conversion, was linear (Figure 2) fitting the equation:

$$
\text { Conductivity }=10 b D a \text {, }
$$

where $a$ and $b$ are coefficients and $D$ is diameter.

The samples subjected to severe dehydration (Figure 2, open circles) had significantly different relationships from the less stressed samples. I was unable to restore initial conductivity fully in the highly stressed samples. Sperry and Tyree (1990) encountered the same problems in coniferous species and suspected irre- 


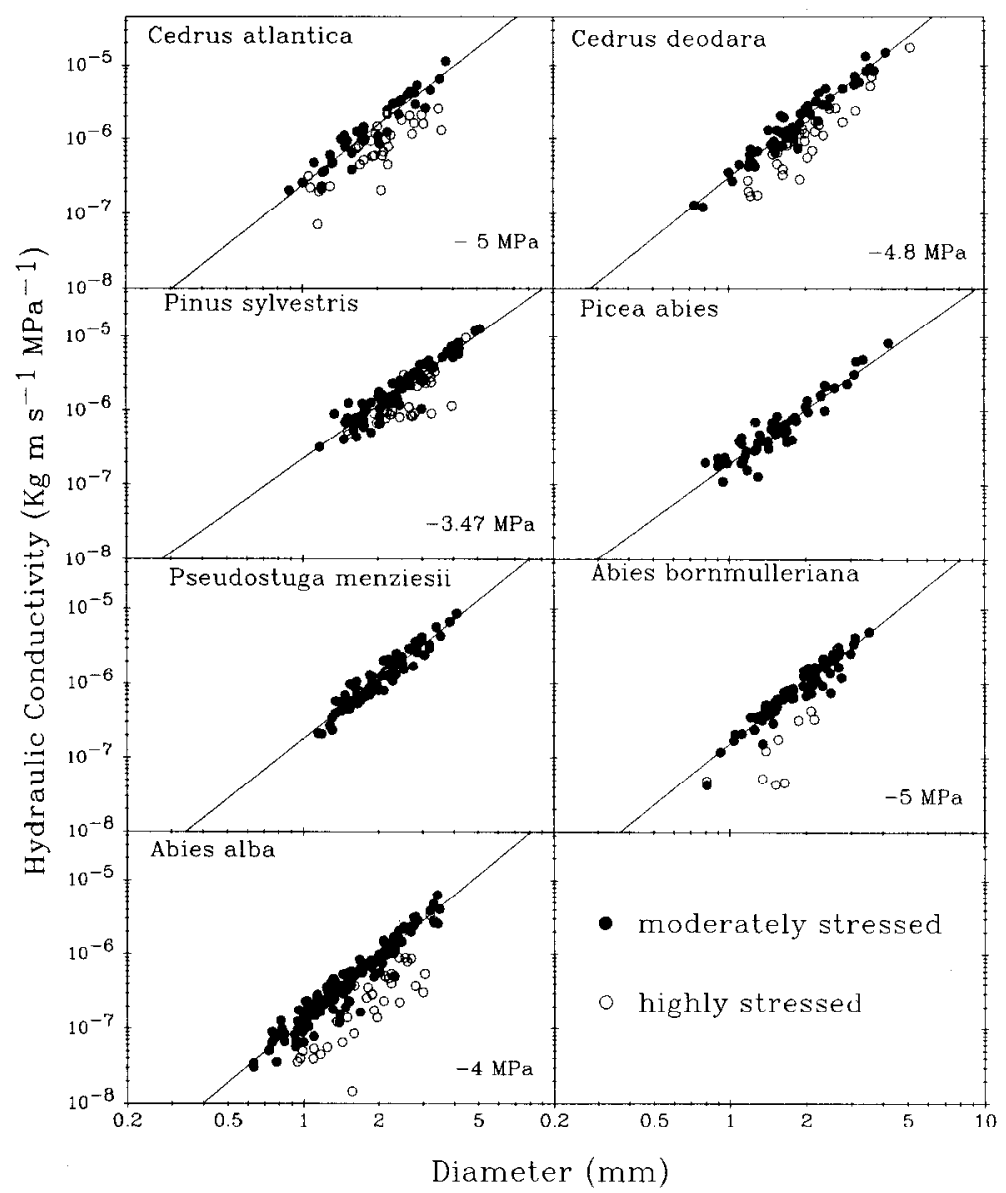

Figure 2. Saturated hydraulic conductivity versus sample diameter (without bark) of seven species of conifers. The saturated hydraulic conductivity is the conductivity after repeated perfusions of de-gassed water to refill the xylem of dehydrated samples. Each point represents one sample. Scales are logarithmic (base 10) to account for the wide range of conductivity values. Values in the graphs indicate the threshold water potential below which the samples are "highly stressed" (open circles). Lines are linear regressions.

versible pit aspiration after extreme dehydration.

The regression curves shown in Figure 3 gave values of coefficient $a$ of $>2$ (Equation 1), showing that permeability (conductivity per cross-sectional area) increased with increasing cross-sectional area. Figure 3 also shows that permeability differed significantly among species, Cedrus species exhibited the highest permeability and Pinus sylvestris and Picea abies the lowest.

\section{Techniques for assessing embolism in conifers}

Vulnerability to air embolisms for all species is shown in Figures 4a-g where the percent loss of hydraulic conductivity and the percent of total AEs are plotted against xylem water potential. For all species, there was a threshold water potential above 


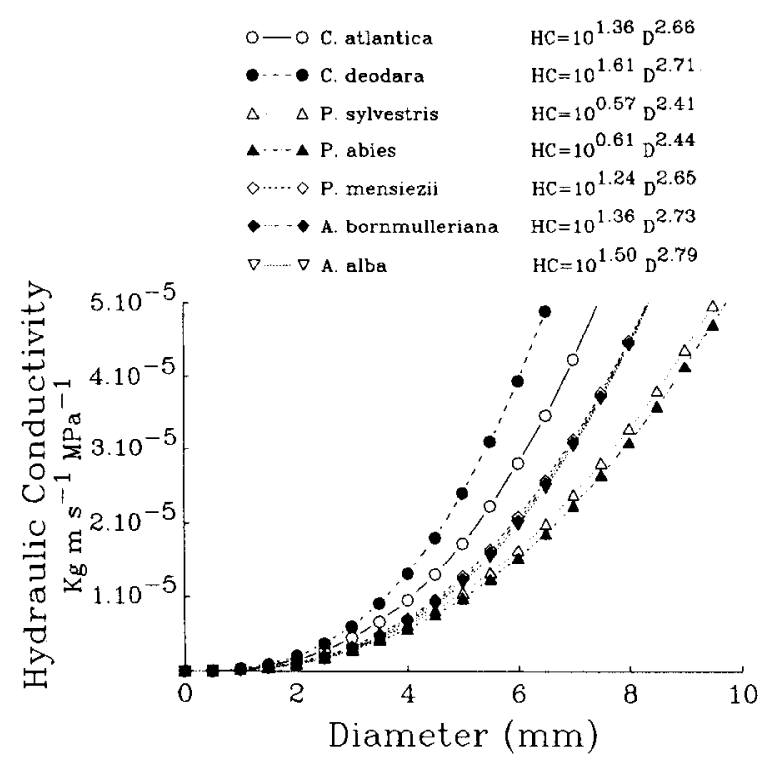

Figure 3. Linear regressions of data from Figure 4. Scales are linear. Equations of the curves are given for each species $\left(\mathrm{HC}=\right.$ Hydraulic conductivity $\left(\mathrm{kg} \mathrm{m}^{-1} \mathrm{~s}^{-1} \mathrm{MPa}^{-1}\right), \mathrm{D}=$ Diameter $(\mathrm{m})$ ).

which no significant loss of conductivity could be detected or only a low percent of AEs was produced. Among species, there were large variations in the threshold potential needed to induce significant embolism in the xylem: Pinus sylvestris was the most vulnerable with a threshold potential around $-2.5 \mathrm{MPa}$, whereas Cedrus atlantica was most resistant to cavitation with a threshold potential around $-4 \mathrm{MPa}$, the other trees exhibiting similar vulnerability with threshold potentials of about $-3 \mathrm{MPa}$.

Within a tree, the smallest and usually youngest branches tended to be less vulnerable than the largest branches (cf. closed and open symbols in Figures 4a-g). This was particularly evident for Cedrus atlantica and Pseudotsuga menziesii.

The vulnerability curve for Abies alba obtained with the pressure chamber technique is shown in Figure 4h. This method gave similar results for both small and large branches unlike the routine air-dehydration procedure, which showed increasing vulnerability with increasing branch size.

When compared with the vulnerability curves obtained by the hydraulic method, the acoustic detection of cavitation gave similarly shaped curves but with a shift toward the right (i.e., toward increased vulnerability) (Figure 4, circles versus triangles). The threshold water potentials were similar for all species except Cedrus deodara, where $\mathrm{AE}$ production started at a water potential around $-3 \mathrm{MPa}$, whereas loss of conductivity was only noticeable below $-4 \mathrm{MPa}$.

The effect of sample length on total AEs is shown on Figure 5. To account for size variations within a branch, I measured the weight/length ratio for each specimen and then computed the total events for a mean weight/length ratio. The $x$ axis represents 


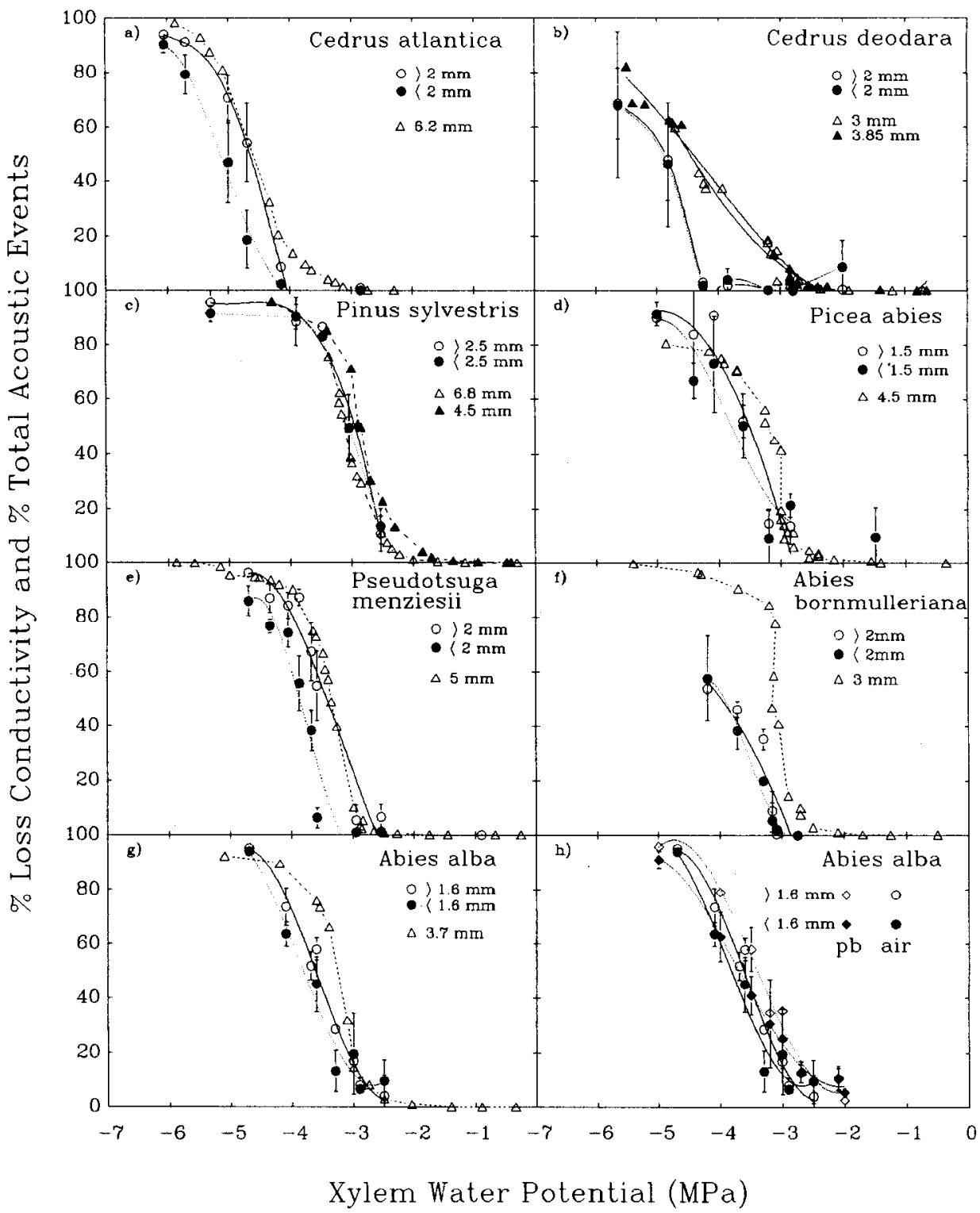

Figure 4. a-g: Vulnerability profiles of several conifers expressed as percent loss of conductivity (circles) or percent total AEs (triangles) versus xylem water potential. Acoustic profiles were obtained on one or two excised branches per species. Each point represents one water potential measurement. Values next to the triangles in the legend are stem diameters (without bark) at the acoustic transducer location. Conductivity profiles were obtained by dehydrating $5-8$ branches per species to a water potential ranging from -2 to $-6 \mathrm{MPa}$. On each branch, the loss of conductivity was estimated on 10 samples excised from internodes. For each species, data were divided in two classes according to their diameters: above the median diameter value (open circles) or below (closed circles). Median diameters are indicated on the graphs. Lines are polynomial fits through the means, bars are $95 \%$ confidence intervals. h: vulnerability profiles expressed as percent loss of conductivity of $\Lambda$ bies alba shoots dehydrated in a pressure bomb ( $\mathrm{pb}$, diamonds and dotted lines) versus routine air dehydration (air, circles and solid lines). 


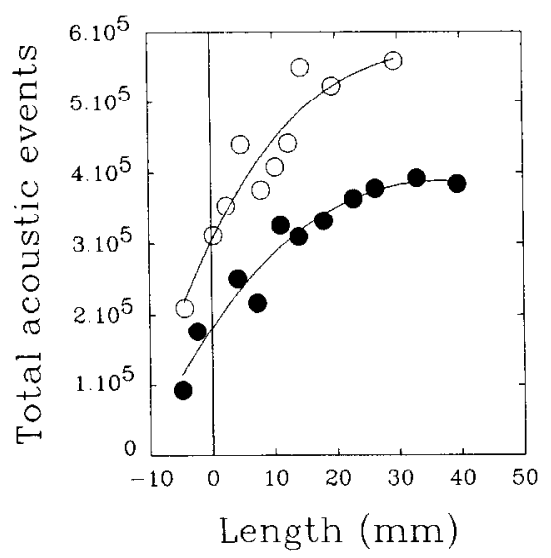

Figure 5. Recording distance of the I51I acoustic transducer. This distance was determined on ca. 3-mm diameter segments of Picea abies var.virgata of various length, debarked and allowed to dehydrate while clamped by their middle on the transducer. The distance on the $x$ axis is ((sample length - transducer diameter $(20 \mathrm{~mm}))$ - mean tracheid length $(1 \mathrm{~mm})) / 2$, negative values correspond to samples smaller than the transducer. The $y$ axis is the total acoustic events produced during drying. The recording distance is the point where the total AEs level off. Different symbols represent different branches. Lines are polynomial fits of the data.

the "distance" between sample and transducer (i.e., (sample length - transducer diameter $(20 \mathrm{~mm}))$ - mean tracheid length $(1 \mathrm{~mm})) / 2$ ) and so negative values correspond to samples smaller than the transducer. The maximum distance from the tracheids at which AEs could be recorded by the transducer was $2-3 \mathrm{~cm}$ (Figure 5).

\section{Discussion}

\section{Methods for assessing embolization in wood}

The hydraulic and acoustic techniques of estimating embolisms in wood only provide comparable results if (1) most of the AEs recorded are produced by cells having conductive function (i.e., vessels and tracheids, not fibers or living cells) and (2) all of the conducting cells individually contribute the same amount to the total conductivity of the tissue. It is thus not surprising that the hydraulic and acoustic techniques gave similar results in coniferous species (Tyree and Dixon 1986) but not in hardwood species (Sperry et al. 1988b, Cochard and Tyree 1990). Our results show a tendency for profiles obtained by the ultrasonic detection of cavitation to indicate greater vulnerability than those obtained by the hydraulic method (Figure 4). This difference probably reflects a sampling problem: the acoustic transducer was clamped on stems that were larger than the ones used to establish hydraulic profiles and, as the transducer recorded AEs a few millimeters around it (Ritman and Milburn 1991), the acoustic profile only describes vulnerability to cavitation at this particular location. The results substantiate the validity of the ultrasonic method for use with conifers. The data also demonstrate that ultrasonic events are closely correlated with cavitation events in tracheids. 
The good agreement between the pressure chamber and the air-drying procedures observed in Abies alba is also found in several other woody species, including ring-porous (Quercus spp.) and diffuse-porous species (Salix, Populus) (Cochard et al. unpublished observations). According to the "air-seeding" hypothesis (Zimmermann 1983), the mechanism of embolism formation is due to the breakdown of air-water menisci at the pit membrane when the pressure difference between both faces of the menisci exceeds a threshold value determined by the diameters of the pores of the membrane. In the pressure chamber expcriment, embolisms might thus be induced either when tensions developed in the xylem while pressure was released inside the pressure chamber, or during the compression phase. Sperry and Tyree $(1988,1990)$ have shown that, in sugar maple and conifer species, embolism could be induced in xylem by injecting segments with pressurized air. In the present study, embolisms occurred as a result of air entry from tracheid to tracheid through the pit membrane when pressure was increased. The pressure chamber method of dehydrating small branches is of practical interest because it is quicker than the air-drying procedure. This may be particularly convenient when dealing with species that lose their needles as soon as water stress develops.

\section{Variations of xylem hydraulic properties in conifers}

The xylem of conifers may be characterized by its permeability (conductivity per cross-sectional area) and by its vulnerability to cavitation.

Within an annual ring, earlywood tracheids cavitate before latewood tracheids (Tyree et al. 1984, Dixon et al. 1984, Sperry and Tyree 1990). This phenomenon has also been demonstrated in wood technology studies, which have shown that the latewood remains permeable to fluid for longer during dehydration than the earlywood (Bramhall and Wilson 1971, Siau 1984).

Within a tree, vulnerability of xylem also varies with stem diameter and branch diameter. The larger the stem or branch the higher the vulnerability. Variations in hydraulic properties within a tree are also correlated with variations in tracheid characteristics: earlywood tracheids are larger than latewood tracheids, and tracheid sizes increase with age and growth rate (Edwards and Jarvis 1982, Tyree 1988, Tyree et al. 1991). The relationship between the vulnerability of a tracheid or a branch and its permeability exemplifies the "efficiency versus safety" dilemma described by Zimmerman (1983). The most efficient conductive conduits are also the most vulnerable.

Vulnerability to cavitation and xylem permeability vary among conifer species. Although there appears to be a trade-off between efficiency and safety when comparing tracheids within a single stem or tree, this is not evident when comparisons are made among species. Sperry and Tyree (1990) compared Abies balsamea, Picea rubens and Juniperus virginiana and found that species with the lowest specific conductivity were also the most resistant to air embolism, whereas I found that although the xylem of Cedrus atlantica had a high permeability, it was the most resistant to cavitation of the species examined (Figure 4).

The relationship between tracheid size and vulnerability may be related to the 
mechanism of embolism formation. Sperry and Tyree (1988) suggested that the cavitation threshold in conifers is a function of pit membrane flexibility and depends on the anatomy of the margo's strands. Within a tree, the flexibility of these strands may vary with the differentiation rate of the tracheids. Slow differentiation may permit more cell expansion and larger tracheids (Roberts et al. 1988) than rapid differentiation, thereby increasing the flexibility of the pit membrane. Among species, tracheids of similar size may have very different pit membrane flexibility.

\section{Ecophysiological importance of xylem embolism}

The water relations of some of the conifers used in this study are well documented. Cedrus atlantica, which has been classified as "drought tolerant," gradually closes its stomata when water stress develops and so is able to maintain photosynthetic activity and transpiration at very low water potential (Grieu et al. 1988, Guehl et al. 1991). “Drought-avoiding" species such as Pinus sylvestris or Abies bornmulleriana, close their stomata very rapidly in response to water stress, and so photosynthesis is reduced during the early stage of drought (Granier and Colin 1990, Guehl et al. 1991).

The xylem of Cedrus atlantica is able to tolerate very low water potential without any embolism induction, this species can thus afford to regulate its water losses moderately. More vulnerable species have to limit transpiration rapidly when drought develops (by means of stomatal closure or even leaf fall) to maintain their xylem potential above the point of dysfunction. Vulnerability curves may thus provide information about the range of xylem tensions a species will be confined in and about its ecophysiological behavior when exposed to drought.

\section{Acknowledgments}

The author gratefully acknowledges G. Aussenac, E. Dreyer, A. Granier, P. Gross, and J.M. Guehl for constructive discussions during this study and two anonymous reviewers for their helpful criticisms.

\section{References}

Aussenac, G. and J.C. Valette. 1982. Comportement hydrique estival de Cedrus atlantica Manetti, Quercus ilex L. et Quercus pubescens Willd. et de divers pins dans le Mont Ventoux. Ann. Sci. For. $39: 41-62$.

Bramhall, G. and J.W. Wilson. 1971. Axial gas permeability of Douglas-fir dried by various techniques. Wood Science 3:223-230.

Cochard, H. and M.T. Tyree. 1990. Xylem dysfunction in Quercus: vessel sizes, tyloses, cavitation and seasonal changes in embolism. Tree Physiol. 6:393-407.

Dixon, H.H. 1914. Transpiration and the ascent of sap in plants. MacMillan, London.

Dixon, M.A., J. Grace and M.T. Tyree. 1984. Concurrent measurements of stem density, leaf and stem water potential, stomatal conductance and cavitation on a sapling of Thuja occidentalis L. Plant, Cell Environ. 7:615-618.

Edwards, W.R.N. and P.G. Jarvis. 1982. Relations between water content, potential and permeability in stems of conifers. Plant, Cell Environ. 5:271-277.

Granier, A. and F. Colin. 1990. Effets d'une sécheresse édaphique sur le fonctionnement hydrique d'Abies bornmulleriana en conditions naturelles. Ann. Sci. For. 47:189-200.

Grieu, P., J.M. Guehl and G. Aussenac. 1988. The effect of soil and atmospheric drought on photosynthesis and stomatal control of gas exchange in three coniferous species. Physiol. Plant. 73:97--104. 
Guehl, J.M., G. Aussenac, J. Bouachrine, R. Zimmermann, J.M. Pennes, A. Ferhi and P. Grieu. 1991. Sensitivity of leaf gas exchange to atmospheric and soil drought and water-use efficiency in some Mediterranean Abies species. Can. J. For. Res. In press.

Ritman, K.T. and J.A. Milburn. 1991. Monitoring of ultrasonic and audible emission from plants with or without vessels. J. Exp. Bot. 42:123-130.

Roberts, S.W., P.B. Gahan and R. Aloni. 1988. Vascular differentiation and plant growth regulators. Springer-Verlag, Berlin, $154 \mathrm{p}$.

Siau, J.F. 1984. Transport process in wood. Springer-Verlag, Berlin, 245 p.

Sperry, J.S. 1985. Xylem embolism in the palm Rhapis excelsa. IAWA Bull, 6:283-292.

Sperry, J.S. and M.T. Tyree. 1988. Mechanism of water stress-induced xylem embolism. Plant Physiol. 88:581-587.

Sperry, J.S. and M.T. Tyree. 1990. Water-stress-induced xylem embolism in three species of conifers. Plant, Cell Environ. 13:427-436.

Sperry, J.S., J.R. Donnelly and M.T. Tyree. 1988a. A method for measuring hydraulic conductivity and embolism in xylem. Plant, Cell Environ. 11:35-40.

Sperry, J.S., M.T. Tyree and J.R. Donnelly. 1988b. Vulnerability of xylem to embolism in a mangrove vs an inland species of Rhizophoraceae. Physiol. Plant. 74:276-283.

Tyree, M.T. 1988. A dynamic model for water flow in a single tree: evidence that models must account for hydraulic architecture. Tree Physiol. 4:195-217.

Tyree, M.T. and M.A. Dixon. 1986. Water stress induced cavitation and embolism in some woody plants. Physiol. Plant. 66:397-405.

Tyree, M.T. and J.S. Sperry. 1989. Vulnerability of xylem to cavitation and embolism. Ann. Rev. Plant. Physiol. Mol. Biol. 40:19-38.

Tyree, M.T., M.A. Dixon, E.L. Tyree and R. Johnson. 1984. Ultrasonic acoustic emissions from the sapwood of cedar and hemlock: an examination of three hypotheses regarding cavitations. Plant Physiol. 75:988-992.

Tyree, M.T., D.A. Snyderman and J.L. Machado. 1991. Water relations and hydraulic architecture of a tropical tree (Schefflera morototoni) : Data, models and a comparison to two temperate species (Acer saccharum and Thuja occidentalis). Plant Physiol. In press.

Zimmermann, M.H. 1983. Xylem structure and the ascent of sap. Springer-Verlag, Berlin, 143 p. 
